\title{
PENDIDIKAN KARAKTER MELALUI AKTIVITAS ZIKIR
}

\author{
Syafrudin \\ Program Studi Informatika, Universitas Indraprasta PGRI \\ Email: syafrudin7575@gmail.com
}

\begin{abstract}
Abstrak
Tujuan penelitian ini adalah (1) Menganalisis prinsip-prinsip ajaran di pengajian Al-Idrisiyyah Jakarta (2) Menganalisis pandangan anggota pengajian Al-Idrisiyyah tentang pendidikan karakter (3) Menganalisis peranan zikir terhadap pendidikan karakter. Penelitian ini menggunakan metode kualitatif yaitu penelitian yang bersifat deskriptif, yang dilakukan di pengajian Al-Idrisiyyah Jakarta. Penelitian ini menggunakan teknik pengumpulan data primer melalui wawancara, observasi, informan, dokumentasi dan triangulasi. Sementara data sekunder diperoleh melalui profile pengajian AlIdrisiyyah Jakarta dan dari pustaka, media internet, jurnal, serta bahan-bahan bacaan lainnya. Hasil temuan penelitian menunjukkan bahwa melalui aktivitas zikir akan membentuk karakter kepribadian yang lebih baik. Semakin banyak intensitas zikir yang dilakukan dengan menggunakan metode yang benar, sesuai tuntunan Al-Qur'an dan As-Sunnah, serta dalam bimbingan seorang guru mursyid, maka akan semakin banyak menghasilkan manfaat dari zikir. Jasmani dan ruhani menjadi lebih sehat, pikiran semakin cerdas dan jiwa menjadi tenang.
\end{abstract}

Kata kunci: Pendidikan Karakter, Aktivitas Zikir

\begin{abstract}
The purpose of this research is to analyze (1) the teaching principles of dhikr in Al-Idrsisiyyah reciting group in Jakarta (2) the views of Al-Idrisiyyah reciting group members on character education (3) the effect of dhikr on character education. This research uses a qualitative method which is a descriptive research conducted in Al-Idrisiyyah reciting group Jakarta. This study uses primary data collection techniques from interviews, observations, informants, documentation and triangulation. While the secondary data are obtained from the profile of Al-Idrisiyyah Qur'an reciting group, the library, internet media, thesis, and other references. The research results indicate that dhikr activity will shape a better personality character. The more intensity of the dhikr performed by using a right method according to Qur'an and Sunnah, as well as guided by a murshid, the more benefits the dhikr activity will bring. The benefits are healthier physicality and spirits, more intelligent mind and peaceful soul.
\end{abstract}

Keywords: Character Education, Dhikr Activiy

\section{PENDAHULUAN}

Manusia membutuhkan pendidikan dalam kehidupannya. Pendidikan merupakan usaha agar manusia dapat mengembangkan potensi dirinya melalui proses pembelajaran dan cara-cara lainnya yang dikenal dan diakui oleh masyarakat [1]. Pendidikan karakter semakin banyak diperbincangkan di tengah-tengah masyarakat Indonesia, terutama oleh kalangan akademisi. Hal ini disebabkan oleh pendidikan yang diajarkan belum secara maksimal dalam memperhatikan aspek moralitas atau akhlak, tetapi hanya menekankan pada aspek pengetahuan kognitif semata. Dengan perhatian yang kurang tersebut akhirnya memunculkan perilaku tidak bermoral, seperti tawuran antar pelajar, pelecehan seksual di lingkungan sekolah, hingga kepada mengkonsumsi obat-obatan terlarang narkoba dan minum-minuman keras, bahkan sampai kepada pembunuhan. Padahal sejak 2500 tahun yang lalu, Socrates telah berkata bahwa tujuan paling mendasar dari pendidikan adalah untuk membuat seseorang menjadi good and smart. Dalam sejarah Islam, sekitar 1400 tahun yang lalu, Nabi Muhammad Saw. telah menegaskan bahwa misi utamanya diutus sebagai seorang Nabi dan Rasul adalah untuk menyempurnakan akhlak dan mengupayakan pembentukan karakter yang baik (good character). Berikutnya, 
ribuan tahun setelah itu, rumusan tujuan utama pendidikan tetap pada wilayah serupa, yakni pembentukan kepribadian manusia yang baik [2].

Pendidikan karakter selain dibangun melalui pendidikan formal, juga bisa dibina melalui pendidikan nonformal, seperti di rumah, mesjid, dan di masyarakat, yang bentuk pendidikan karakternya adalah seperti majelis taklim. Diantara kegiatan yang akhir-akhir ini banyak dikembangkan oleh majelis-majelis taklim atau pengajian dalam meningkatkan pendidikan karakter adalah aktifitas zikir, dan salah satu tempat pelaksanaan zikir yang konsisten dalam melakukan pembinaan pendidikan karakter adalah pengajian Al-Idrisiyyah Jakarta.

Berangkat dari heterogenitas problematika yang dihadapi masyarakat modern khususnya orang-orang yang tinggal di perkotaan saat ini seperti Jakarta, maka ada beberapa hal yang menarik dari pengajian yang diselenggarakan perlu untuk dicermati. Pertama, pembinaan pendidikan karakter melalui aktifitas zikir dalam menghadapi perubahan sosial dua dekade terakhir cukup baik dan teruji. Kedua, pengajian dengan aktifitas zikir mampu menjadi madrasah atau sekolah dalam membentuk pendidikan karakter dan patut diberi apresiasi mengingat pengikut atau jamaah tersebar di seluruh wilayah Jakarta.

\section{METODE}

Penelitian yang digunakan adalah penelitian yang bersifat kualitatif yaitu penelitian yang bermaksud untuk memahami fenomena tentang apa yang dialami oleh subjek penelitian misalnya perilaku, persepsi, motivasi, tindakan, dan lain-lain, secara holistik, dan dengan cara deskriptif dalam bentuk kata-kata dan bahasa, pada suatu konteks khusus yang alamiah [3].
Penelitian ini tidak menggunakan angkaangka, namun berupa pengumpulan data melalui naskah wawancara, catatan lapangan, dokumentasi pribadi, pengamatan, dan catatan resmi lainnya, sehingga dari penelitian kualitatif ini akan menghasilkan gambaran yang komprehensif atau sesuai dengan realita yang terjadi di lapangan secara lengkap, terperinci, dan mendalam. Metode kualitatif merupakan metode penelitian yang menggunakan latar alamiah, dan peneliti sebagai instrumen kunci dengan teknik pengumpulan data secara gabungan, analisis data yang bersifat induktif, dan hasil penelitiannya lebih kepada makna yang dihasilkan dari pada generalisasi.

Metode penelitian kualitatif deskriptif adalah suatu metode yang digunakan untuk menemukan pengetahuan terhadap subjek penelitian pada suatu saat tertentu. Kata deskriptif berasal dari bahasa latin "descriptivus" yang berarti uraian. Penelitian kualitatif deskriptif berusaha mendiskripsikan seluruh kegajala atau keadaan yang ada, yaitu keadaan gejala menurut apa adanya pada saat penelitian dilakukan [4].

Menurut Sugiyono, penelitian kualitatif harus bersifat "perspektif emic" yaitu memperoleh data bukan "sebagaimana seharusnya", bukan berdasarkan apa yang dipikirkan oleh peneliti, namun berdasarkan sebagaimana adanya yang terjadi di lapangan, yang dialami, dirasakan, dan dipikirkan oleh partisipan atau sumber data [5]. Penelitian ini bertujuan mendiskripsikan lebih dalam mengenai berbagai strategi pembentukan karakter jamaah di lembaga Tarekat AlIdrisiyyah Jakarta.

Penelitian ini dilaksanakan di lembaga pendidikan nonformal yaitu Tarekat AlIdrisiyyah yang berlokasi di Jl Batu Tulis XIV No. 4 Kel. Kebon Kelapa Kec. 
Gambir Jakarta Pusat. Penelitian ini dilakukan selama enam bulan, mulai dari bulan Nopember 2013 sampai dengan bulan April 2014

Teknik pengumpulan data dalam penelitian ini dilakukan dengan wawancara, yaitu percakapan dengan maksud tertentu. Percakapan itu dilakukan oleh dua pihak, yaitu pewawancara (interviewer) yang mengajukan pertanyaan dan terwawancara (interviewe) yang memberikan jawaban atas pertanyaan itu. Dalam penelitian ini, peneliti mengumpulkan data dari informan. Informan merupakan data primer yang mampu memberikan informasi mengenai keadaan objek yang diteliti atau memberikan informasi tentang lingkungan di sekitar objek.

Informan yang di ambil dari beberapa jamaah, seperti pengurus lembaga alIdrisiyyah dan jamaah umum pengajian yang terdiri dari orang-orang terpelajar sampai masyarakat yang awam, peneliti akan mencari data sebanyak-banyaknya mengenai kegiatan objek melalui informan tersebut. Selanjutnya data yang terhimpun dari informan adalah data yang bukan diusahakan sendiri pengumpulannya oleh peneliti, namun data tersebut merujuk pada kedekatan objek pada informan yang dapat menguatkan apa saja kegiatan yang dilakukan objek penelitian.

\section{HASIL DAN PEMBAHASAN Pendidikan Karakter}

Ahmad D. Marimba, menjelaskan bahwa pendidikan adalah bimbingan atau didikan secara sadar oleh pendidik terhadap perkembangan anak didik, baik jasmani maupun ruhani, menuju terbentuknya kepribadian yang utama [6]. Menurut Adian, menggambarkan karakter laksana "otot", yang akan menjadi lembek jika tidak dilatih. Dengan latihan demi latihan, maka 'otot-otot' karakter akan menjadi kuat dan akan mewujud menjadi kebiasaan (habit). Orang yang berkarakter tidak melaksanakan suatu aktivitas karena takut akan hukuman, tetapi karena mencintai kebaikan (loving the good). Karena cinta itulah, maka muncul keinginan untuk berbuat baik (desiring the good) [7]. Menurut Erie Sudewo pendidikan karakter adalah pendidikan untuk membentuk kepribadian seseorang melalui pendidikan budi pekerti, yang hasilnya terlihat dalam tindakan nyata seseorang, yaitu tingkah laku yang baik, jujur, bertanggung jawab, menghormati hak orang lain, kerja keras, dan sebagainya.[8].

\section{Urgensi Pendidikan Karakter}

Pendidikan karakter seharusnya membawa peserta didik ke pengenalan nilai secara kognitif, penghayatan nilai secara afektif, dan akhirnya kepada pengamalan nilai secara nyata. Permasalahan pendidikan karakter yang selama ini ada di sekolah misalnya, perlu segera dikaji dan dicari alternatif-alternatif solusinya serta perlu dikembangkan secara lebih operasional sehingga mudah diimplementasikan. Banyak hasil penelitian yang membuktikan bahwa karakter seseorang dapat mempengaruhi kesuksesannya. Diantaranya berdasarkan penelitian di Harvard University, Amerika Serikat, yang menyatakan bahwa ternyata kesuksesan seseorang tidak ditentukan semata-mata oleh pengetahuan dan kemampuan teknis (hard skill) saja, tetapi lebih kepada kemampuan mengelola diri dan orang lain (soft skill). Penelitin ini mengungkapkan bahwa kesuksesan hanya ditentukan sekitar 20 persen oleh hard skill dan sisanya 80 persen oleh soft skill. Bahkan orang-orang tersukses di dunia bisa berhasil karena lebih banyak didukung kemampuan soft skill dari pada hard skill. Hal ini mengisyaratkan bahwa mutu pendidikan karakter perserta didik sangat urgen untuk ditingkatkan [9]. Untuk meningkatkan pendidikan karakter, perlu pemahaman yang mendalam tentang hakikat 
pendidikan karakter. Hal ini penting, karena pendidikan karakter bergerak dari kesadaran (awareness), pemahaman (understanding), kepedulian (concern), dan komitmen (commitment), menuju tindakan (doing atau acting) [10]. Oleh karena itu, keberhasilan pendidikan karakter di sekolah sangat bergantung pada ada tidaknya kesadaran, pemahaman, kepedulian, dan komitmen dari semua warga sekolah terhadap penyelenggaraan pendidikan karakter tersebut. Moral understanding sebagai aspek pertama yang harus diperhatikan dalam pendidikan karakter memiliki enam unsur, yaitu kesadaran moral (moral awareness), pengetahuan tentang nilai-nilai moral (knowing about moral values), penentuan sudut pandang (perspective taking), logika moral (moral reasoning), keberanian mengambil keputusan (decision making), dan pengenalan diri (self knowledge). Keenam unsur tersebut merupakan komponen-komponen yang harus ditekankan dalam pendidikan karakter, serta diajarkan kepada peserta didik dan diintegrasikan dalam seluruh sistem pembelajaran.

\section{Zikir}

Menurut Muhammad Arifin Ilham zikir artinya ingat dan sebut. Karena ingat maka disebut, dan disebutnya adalah karena ingat. Dengan demikian zikrullah berarti mengingat dan menyebut asma (nama) Allah. Ingat adalah gerak hati, sedangkan sebutan adalah gerak lisan. Zikir dalam hati lebih baik dibandingkan dengan dzikir lisan semata. Namun jauh lebih sempurna jika keduanya dipadukan. Jadi zikir yang terbaik adalah perpaduan antara zikir hati dan lisan. Hati mengingat Allah dan lisan menyebut-Nya. Itulah makna awal dari khusuk [11].

Menurut Didin Hafidhuddin, makna berzikir sangatlah luas mulai dari menyebut asma Allah, memuji kebesaran dan keagungan-Nya dengan lisan dan hati, mengucapkan kata-kata yang baik, menebarkan salam dan kedamaian, menjauhkan diri dari ghibah, fitnah, dan mempergunjingkan orang lain, serta mengaflikasikan nilai-nilai Ilahi dalam seluruh tatatanan kehidupan. Selanjutnya menurut beliau, pedagang yang berzikir misalnya adalah pedagang yang di dalam muamalah dan transaksinya senantiasa menjunjung tinggi kejujuran, dan tidak mau menipu konsumen hanya karena mengejar keuntungan yang banyak. Pejabat yang berzikir adalah pejabat yang berusaha melaksanakan tugas dan kewajibannya serta memberikan pelayanan seoptimal mungkin kepada masyarakat dengan landasan pengabdian kepada Allah Swt. Profesional yang berzikir adalah profesional yang melaksanakan keahliannya dengan tujuan memberikan manfaat yang sebesar-besarnya kepada masyarakat atas dasar ihsan kepada-Nya, dan bukan hanya untuk kepentingan diri dan keluarga semata [12].

Menurut M. Quraish Shihab, zikir dalam pengertian luas adalah kesadaran tentang kehadiran Allah di mana dan kapan saja, serta kesadaran akan kebersamaan-Nya dengan makhluk; kebersamaan dalam arti pengetahuan-Nya terhadap apa pun di alam raya ini serta bantuan dan pembelaan-Nya terhadap hamba-hamba-Nya yang taat. Zikir dalam peringkat inilah yang menjadi pendorong utama melaksanakan tuntunanNya dan menjauhi larangan-Nya, bahkan hidup bersamanya [13]. Sedangkan menurut Syekh Akbar M. Fathurrahman, Zikir bermakna membangun komunikasi dengan Allah, supaya tindakannya dalam kesadaran diawasi oleh Allah. Maka hati yang tidak dilatih untuk tersambung dengan Allah akan bersuara kecil tatkala ada godaan nafsu. Godaan seperti melakukan korupsi misalnya, hati kecilnya melarang. Namun, suaranya yang kecil tidak mampu menghadang suara hawa 
nafsunya yang lebih besar dan kuat. Akhirnya, korupsinya tetap dilakukan karena suara hatinya lemah lantaran tidak diasah dengan latihan zikir yang kuat [14].

\section{Urgensi Zikir}

Untuk mencapai ketenteraman dan kesejukan melalui zikir tidak bisa sekedar teori dan wacana yang diangankan. Zikir bukanlah gerak 'rasio an sich', tetapi gerak 'rasa' (dzauq). Pencapaiannya haruslah dengan upaya yang maksimal dan berkesinambungan (istiqamah). Selain itu, diperlukan tarekat (metode/jalan) serta mursyid (pembimbing). Adapun tujuannya tiada lain kecuali mengantarkan zakirin (orang yang berzikir) untuk mencapai kekhusyu'an (damai dan tenang).

Disamping itu, zikir juga memberikan kemanfaat tidak hanya kepada jiwa atau psikologi tetapi juga kepada tubuh atau fisik. sebagaimana menurut Arman, bahwa ada hubungan yang erat antara pelafalan huruf (makhrajil huruf) pada bacaan zikir dan tampilan klinis (kondisi fisik dan psikis seseorang). Seringnya terjadi perubahan yang cukup signifikan ke arah penyembuhan pada pasien-pasien yang terbiasa berzikir dengan khusuk dan khidmat dibanding pasien lain yang tidak pernah berzikir atau yang zikirnya asalasalan meskipun keduanya memiliki gejala penyakit yang sama [15].

Pengajian Al-Idrisiyyah Jakarta sebagai salah satu objek penelitian kali ini, telah banyak memberikan kontribusi kepada perubahan karakter yang lebih baik khususnya kepada para jamaah yang mengikuti aktivitas zikir mulai dari kalangan akademisi, seperti dosen dan mahasiswa, pegawai negeri dan pegawai swasta, sampai kalangan pedagang dan pelajar. Mereka datang dari berbagai daerah sekitar Jakarta, seperti Bogor, Bekasi, Depok, dan Tangerang.
Pengajian ini adalah merupakan salah satu lembaga pendidikan nonformal yang hadir di lingkungan masyarakat sebagai salah satu wadah untuk membantu melakukan perbaikan karakter ke arah yang lebih baik. Hal ini bisa dilihat dari beberapa alasan yang disampaikan oleh sebagian anggota jamaah, yaitu : 1) Melalui aktivitas zikir, akan membuat jasmani dan rohani menjadi sehat. Sebagaimana yang disampaikan oleh informan ke-1 dan informan ke-2, informan ke-8, dan informan ke-10n. Hal ini sesuai dengan teori Arman Yurisaldi Saleh yang mengatakan bahwa zikir juga bermanfaat untuk kesehatan tubuh seperti banyak para ilmuwan dan ahli kedokteran yang mencoba meneliti hubungan antara doa atau zikir dan kesehatan fisik manusia. Sejalan dengan teori tersebut, maka kegiatan aktivitas zikir yang diadakan di pengajian Al-Idrisiyyah Jakarta selalu menggunakan metode atau cara zikir dalam keadaan duduk dan berdiri. Melalui metode zikir berdiri yaitu dengan menggerakkan beberapa anggota tubuh seperti tangan, kepala dan badan, akan menghasilkan kesehatan tubuh seperti halnya berolah raga. 2) Melalui aktivitas zikir akan mendapatkan ketenangan jiwa, terhindar dari kemaksiatan, dan mudah menyelesaikan problematika yang dihadapi karena tumbuh sifat optimis. Sebagaimana yang diungkapkan oleh informan ke-3, informan ke-4, informan ke-5, informan ke-7. Hal ini sesuai dengan teori menurut Syeikh Akbar Muhammad Fathurrahman, bahwa dengan zikir hati akan tersambung dengan Allah dan merasa diawasi, sehingga terhindar dari maksiat. 3) Melalui aktivitas 
zikir akan membentuk pola pikir (mind set) yang baik, menambah keyakinan (tauhid) kepada Allah, terhindar dari sifat-sifat buruk seperti berbohong, menipu, dan mengendalikan diri dari keinginan hawa nafsu, serta menumbuhkan kecintaan kepada keluarga, lingkungan dan sesama muslim. Sebagaimana yang disampaikan oleh informan ke-9, informan ke-11, informan ke-12, dan informan ke-13. Hal ini sesuai dengan teori menurut Quraish Shihab yang mengutip pendapat Ghazali, bahwa zikir bermanfaat sebagai cahaya hati guna meraih pengetahuan dan hikmah, membentuk pribadi yang berwibawa, mencintai pihak lain, memiliki harga diri sehingga tidak merasa butuh selain Allah, dan keberkahan dalam jiwa, ucapan, perbuatan, pakaian, bahkan tempat melangkah dan duduk.

Sejalan dengan teori tersebut, aktivitas zikir yang diselenggarakan di pengajian Al- Idrisiyyah Jakarta, telah mampu memberikan semangat untuk mengembangkan pola berfikir yang sehat dan positif dalam pengembangan ilmu pengetahuan. Hal ini bisa dilihat sebagaimana di tabel 1 .

Tabel 1. Matriks Perubahan Jamaah Al Idrisyiah Sebelum dan Sesudah Mengikuti Aktifitas Zikir

\begin{tabular}{clll}
\hline No & \multicolumn{1}{c}{ Nama } & \multicolumn{1}{c}{ Sebelum } & \multicolumn{1}{c}{ Sesudah } \\
\hline 1 & Informan ke-1 & Kecanduan narkoba & Sembuh dari kecanduan narkoba \\
2 & Informan ke-2 & Gemar dengan kemaksiatan & Terhindar dari kemaksiatani \\
3 & Informan ke-3 & Gemar dengan kemaksiatan & Terhindar dari kemaksiatan \\
4 & Informan ke-4 & Keras kepala & Mudah menerima nasehat \\
5 & Informan ke-5 & Egoisme pemikiran & Toleransi kepada sesama \\
6 & Informan ke-6 & Jiwa yang labil & Jiwa yang tenang \\
7 & Informan ke-7 & Jiwa yang pesimis & Jiwa yang optimis \\
8 & Informan ke-8 & Pribadi yang bakhil & Pribadi yang dermawan \\
9 & Informan ke-9 & Pola pikir sekuler & Memiliki mindset Islami \\
10 & Informan ke-10 & Tidak memahami ajaran Islam & Mampu memahami ajaran Islam \\
11 & Informan ke-11 & Kurang peduli lingkungan & Peduli terhadap lingkungan \\
12 & Informan ke-12 & Nafsu syahwat yang berlebihan & Mampu mengendalikan hawa nafsu \\
13 & Informan ke-13 & Jiwa yang labil & Jiwa yang tenang \\
\hline
\end{tabular}

\section{SIMPULAN}

Melalui penelitian ini, maka dapat diambil beberapa kesimpulan diantaranya: 1) Pengajian Al-Idrisiyyah Jakarta telah mampu memberikan kontribusi dalam pembentukan karakter terutama yang aktif menghadiri pengajian taklim dan zikir. 2) Bahwa lembaga pengajian Al-Idrisiyyah Jakarta adalah merupakan salah satu lembaga pendidikan nonformal yang bisa dijadikan solusi dalam pembentukan karakter anak didik. 3) Bahwa melalui ibadah zikir yang dilakukan secara terus menerus dengan seorang pembimbing, maka akan menghasilkan kepribadian yang berkarakter atau berakhlak mulia.

\section{DAFTAR PUSTAKA}

[1] Helmawati. "Pendidikan Nasional dan Optimalisasi Majelis Ta'lim". Jakarta: Rineka Cipta, 2013.

[2] Majid, Abdul, dan Dian Andayani. "Pendidikan Karakter Perspektif Islam". Bandung: Remaja Rosdakarya, 2011.

[3] Moleong, Lexy J. "Metodologi Penelitian Kualitatif'. Bandung: Remaja Rosdakarya, 2013.

[4] Mukhtar. "Metode Praktis Penelitian Deskriptif Kualitatif'. Jakarta: Referensi, 20

[5] Sugiyono. "Metode Penelitian Kuantitatif, Kualitatif dan R \& D". Bandung: Alfabeta, 2012 
[6] Kurniawan, Syamsul. "Pendidikan Karakter; Konsepi \& Implementasinya Secara Terpadu di Lingkungan Keluarga, Sekolah, Perguruan Tinggi, \& Masyarakat". Yogyakarta: R-Ruzz Media, 2013.

[7] Husaini, Adian. "Pendidikan Islam Membentuk Manusia Berkarakter \& Beradab". Jakarta: Cakrawala Publishing, 2012

[8] Sudewo, Erie. "Best Pracrice Character Building Menuju Indonesia Lebih Baik". Jakarta: Republika Penerbit, 2011.

[9] Zubaedi. "Desain Pendidikan Karakter; Konsep dan Aplikasinya dalam Lembaga Pendidikan". Jakarta: Kencana, 2011.

[10] Mulyasa. "Manajemen Pendidikan Karakter". Jakarta: Bumi Aksara, 2013.

[11] Arifin Ilham, Muhammad. "Renungan-Renungan Zikir". Jakarta: Intuisi Press, 2004.

[12] Hafidhuddin, Didin. "Membentuk Pribadi Qur'an; Di Bawah Bimbingan Syari'ah". Jakarta: Harakah, 2002.

[13] Shihab, M. Quraish. "Wawasan AlQur'an Tentang Zikir \& Doa”. Jakarta: Lentera Hati, 2008.

[14] Fathurrahman, Syekh Akbar Muhammad. "Jalan Menuju Tuhan; Memahami dan Mengamalkan Islam secara Komprehensif dan Terpadu". Jakarta: Grasindo, 2016.

[15] Saleh, Arman Yurisaldi. "Berzikir untuk Kesehatan Saraf". Jakarta: Penerbit Zaan, 2010 